\title{
Sertleştirilmiş Silindirik Düz Dişli Çarkın Statik Eğilme Dayanımının Güvenirlik Analizi
}

\author{
Reliability Analysis of the Static Bending Strength of Cylindrical Hardened Gears
}

\author{
Mehmet BOZCA ${ }^{1}$ \\ ${ }^{1}$ Yıldız Teknik Üniversitesi, Makina Fakültesi, Konstrüksiyon Anabilim Dalı34349 Yıldız, İstanbul, Türkiye
}

Öz

Bu çalışmanın amacı sertleştirilmiş silindirik düz dişli çarkın statik eğilme dayanımını güvenirlik analizi temelinde incelemektir. Bu amaç için, bilye-püskürtülmüş ve bilye-püskürtülmemiş farklı çekirdek ve yüzey sertliği değerlerine sahip dişli çarklar bir yarı-statik yükleme koşulu sağlayan bir pulsator test makinasında test edilmiştir. Test edilen tüm dişli çark numunelerinin malzemeleri $20 \mathrm{MnCr} 5$ çeliğidir ve aynı geometriye sahiptirler. Diş kırılması için yarı-statik yükleme durumu deneysel olarak gözlemlenmiş ve ölçülmüştür. Hasara sebep olan uygulanan yük için eğilme gerilmeleri hesaplanmıştr. Yüzeyden başlayan diş-dibi hasarları deneysel olarak gözlemlenmiştir. Bilye-püskürtme işleminin statik yükleme koşullarında dişin eğilme dayanımı üzerinde hiç olumlu etkisinin olmadığ belirlenmiştir. Sertleştirilmiş silindirik düz dişli çarkın statik eğilme dayanımı güvenirlik analizi gerçekleştirilmiştir. Statik eğilme dayanımının ortalama değerleri, standart sapmalar ve standart değişkenleri hesaplanmıştır. Statik eğilme dayanımının güvenirlik seviyelerinin literatürde verilen dayanım değerlerini sağladığı sonucuna varılmıştır.

Anahtar kelimeler: Sertleştirilmiş dişli çark, Bilye-püskürtme, Eğilme dayanımı, Güvenirlik.

\begin{abstract}
The target of this study is to investigate the static bending strength of teeth in cylindrical hardened gears based on reliability analysis. The effect of hardness on the static bending strength of the tooth of the cylindrical gear was investigated in the static loading conditions. The gears were carburized with low-pressure in a 4 mbar acetylene atmosphere and cooled with gas. In order to obtain different hardness values, different cooling rates were applied using different gases and gas-pressures. For this objective, shot-peened and unshot-peened gears having different core and surface hardness values are tested on a pulsator test machine providing a quasi-static loading condition. Shot peening treatment was performed according to Atmen A and Atmen N method. Material used for gear samples is $20 \mathrm{MnCr} 5 \mathrm{steel}$ and samples have the same geometry. The quasi-static load for tooth fracture is monitored and measured. The bending stresses for applied load which causes fracture is calculated. Tooth-root failures starting from the surface are experimentally observed. The shot-peening treatment is found to have no positive effect on the bending strength of the tooth under static loading conditions, although the shot peening treatment is effective in improving the dynamic bending strength of the gears. The increase in the hardness value results in an increase in the static bending strength of the gears. A high static bending strength value was obtained for high-rigidity gears heat-treated in a 20 bar Helium (He) atmosphere. The hardness of the core has been shown to have no significant effect on the determination of the static bending strength of the gears since the damage occurred from the surface. The appearance of the damage surfaces for gears is typical static loading damage from the surface, depending on the maximum tensile stress of the crack. Reliability involves the damage behavior of a product and is therefore an important criterion for product assessment. Gears are the most important machine elements in many mechanical power transmission systems and therefore the reliability of the gears is very important. Reliability analysis is required to determine the possible strength values of the gears to meet the strength values foreseen in the literature. Reliability analyses of the static bending strength of the tooth in cylindrical hardened gears are conducted. The mean values, standard deviations and standard variables of the static bending strength are calculated. It is concluded that the reliability levels of the static bending strength satisfy the required strength values given in the literature.
\end{abstract}

Keywords: Hardened gears, Shot-peening, Bending strength, Reliability. 


\section{GİRIŞ̧}

$\mathrm{Bu}$ çalışmanın amacı sertleştirilmiş silindirik düz dişli çarkın statik eğilme dayanımını güvenirlik analizi temelinde incelemektir. Statik yükleme koşullarında silindirik düz dişli çarkın dişinin eğilme dayanımına sertliğin etkisi incelenmiştir. Bilye-püskürtülmüş ve bilye-püskürtülmemiş farklı sertliğe sahip dişli çarklar yarı-statik yükleme koşullarında pulsator test makinasında test edilmiştir.

Dişli çarkların mukavemetini arttırmak için çeşitli ısıl işlemlerin uygulanması gerekir. Sertleştirme işlemi ile yüzeyde dayanımı arttırıcı sert bir tabaka oluşturulur.

Isıl işlemlerin amacı genellikle aşınmaya ve yorulmaya karşı dayanıklı yüzeyler elde etmektir. Elde edilen yüzey tabakası yüzeydeki bası gerilmeleri ile birlikte yorulma dayanımının arttırılmasında çok etkili olabilir [1].

Yüzey sertleştirme, çelik alaşımlarının yüzey sertliğini ve yorulma ömrünü artırmak için sıkça kullanılan bir ısıl işlemdir. $\mathrm{Bu}$ sertleştirme işlemi bir karbürleme veya nitrürleme işlemi tarafından gerçekleştirilir. Bir parça, yüzey sertleştirme esnasında, bir yüksek sıcaklıkta karbonlu veya azotlu bir atmosfer etkisindedir. Karbon veya azot bakımından zengin bir yüzey tabakası gaz fazından atomik bir difüzyonla ortaya çıkar [2].

Yüzey sertleştirme ile çelik bir karbürizasyon sürecine girer. Yüzey sertleştirme işlemi esnasında, ürün karbon açısından zengin bir dış yüzey elde eder, böylece yüzey sertliği ve yorulma ömrü $\operatorname{artar}[3]$.

Dişli çarkların mukavemetini arttırmak için mekanik yüzey işlemlerin de uygulanması gerekir. Bilye püskürtme işlemi ile yüzeyde bası gerilmeleri oluşturulur.

Bilye-püskürtme metal parçaların yorulma dayanımlarını iyileştirmek için kullanılan bir mekanik yüzey işlemidir. Bilye-püskürtme işleminde yüksek sertlik değerine sahip küçük bilyeler yüzeye basınçla püskürtülür [4].

Bilye-püskürtme dişli çark gibi makina elemanlarının yorulma özelliklerini geliştirir. Bilye-püskürtme ile artık gerilmeler ve yüzey pürüzlükleri azaltılır ve yüzey tabakasındaki çalışma sertliği geliştirilir. Ayrıca, bilye-püskürtme işlemi çeşitli endüstrilerde maliyetleri azaltmak ve verimliliği artırmak için fayda sağlayabilir [3].

Bası gerilmeleri yorulma hasarı dayanımını, korozyon yorulması hasarını ve gerilme korozyonu çatlamasını, hidrojen gevrekliği çatlamasını ve aralık korozyonunun dayanımını artırmak için faydalıdır [5,6].

Artık basma gerilmeleri genel olarak bilye-püskürtme işlemi esnasında dış yüzey bölgesi içindeki bölgesel plastik deformasyon ile sünek metallere mekanik olarak uygulanir [5].
Sertleştirilmiş bir silindirik düz dişli çarkın dişinin statik eğilme dayanımına çekirdek sertliğinin etkisi deneysel olarak incelenmiştir. Çekirdek sertliğinin statik yükleme koşullarında dişin eğilme dayanımına hiç dikkate değer bir etkisinin olmadığ

Dişli çarkın deneysel olarak elde edilen mukavemet değerlerinin literatürde ön görülen mukavemet değerlerini karşılayabilme olasılığını belirlemek için güvenirlik analizi yapılması gerekir.

VDI 4001 (Verein Deutscher Ingenieure - Handbuch Technishe Zuverlässigkeit) (Alman Mühendisler Odası - Teknik Güvenirlik El Kitabı) direktifine göre [8] güvenirlik belirli bir süre boyunca bir ürünün belirli işlevsel ve çevresel koşullar altında hasara uğrama olasılığıdır. Güvenirlik bir ürünün hasar davranışını içerir ve bundan dolayı ürün değerlendirmesi için önemli bir kriterdir.

Dişli çarklar, birçok mekanik güç iletim sistemlerinde en önemli makine elemanlarıdır ve bu yüzden dişli çarkların güvenirlik analizleri çok önemlidir [9]. Dişli çarklar birçok durumda, yüksek hızlarda yüksek yük altında ve titreşim altında çalıştıklarından dolayı, dişli çarkların hasar türleri, diş dibi kırılması, yüzey basıncı hasarı (pitting) ve yenme (scuffing) olarak çeşitlenir [9]. Bu yüzden, dişli çarkların mukavemet değerlerinin güvenirliği önem kazanır.

Bu çalışma aşağıdaki şekilde düzenlenmiştir. Bölüm 2 de uygulanan metot sunulmuştur. Metot bölümünde, sertleştirilmiş düz dişli çark numunelerinin geometrisi, malzemesi, uygulanan ısıl işlemler ve bilye püskürtme işlemi açıklanmıştır. Test sonuçları da bu bölümde sunulmuştur. Bölüm 3 de güvenirlik analizi açıklanmış ve bölüm 4 de ise sonuçlar ve tartışma sunulmuştur. Çalışmadan elde edilen sonuçlar bölüm 5 de özetlenmiştir.

\section{II.METOT}

$\mathrm{Bu}$ çalışmada sertleştirilmiş silindirik düz dişli çarkın statik eğilme dayanımını belirlemek ve belirlenen dayanım değerlerinin güvenirlik analizini gerçekleştirmek için aşağıdaki işlem sırası uygulanmıştır. Uygulanan işlemlerin akış şeması Şekil 1 de görülmektedir. 


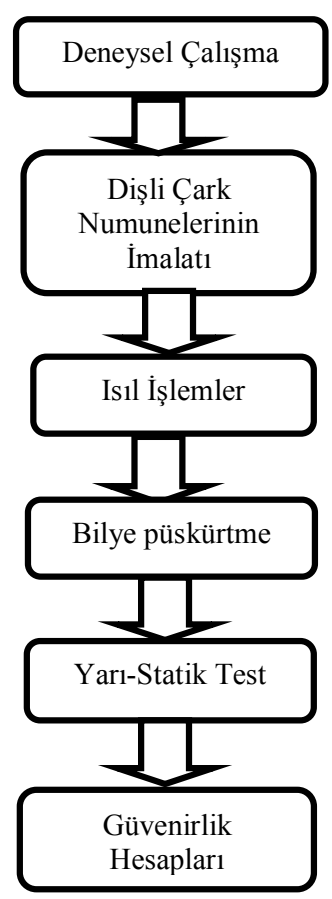

Şekil 1. Deneysel çalışmanın akış diyagramı

\subsection{Sertleştirilmiş Düz Dişli Çark Numuneleri}

Dişli çark numuneleri statik yüklemede diş-dibinin eğilme dayanımını belirlemek için pulsator test makinasında test edilmiştir.

\subsubsection{Dişli çark geometrisi}

Dişli çark geometrisi olarak otomotiv transmisyonunda sıkça kullanılan silindirik düz dişli çark seçilmiştir. Dişli çark geometrisi parametreleri Tablo 1'de verilmektedir. Bir silindirik düz dişli çark numunesinin görünümü Şekil 2 de görülmektedir.
Tablo 1. Dişli çark geometrisi parametreleri

\begin{tabular}{|l|l|l|l|}
\hline Dişli parametreleri & Sembol & Birim & Değer \\
\hline Normal modül & $\mathrm{m}_{\mathrm{n}}$ & {$[\mathrm{mm}]$} & 5 \\
\hline Diş genişliği & $\mathrm{b}$ & {$[\mathrm{mm}]$} & 30 \\
\hline Kavrama açıs1 & $\alpha$ & {$\left[{ }^{0}\right]$} & 20 \\
\hline Diş sayıs1 & $\mathrm{Z}$ & {$[\mathrm{adet}]$} & 24 \\
\hline Diş dibi çap1 & $\mathrm{d}_{\mathrm{a}}$ & {$[\mathrm{mm}]$} & 130 \\
\hline Ortalama dairesi çap1 & $\mathrm{d}_{0}$ & {$[\mathrm{~mm}]$} & 120 \\
\hline Yüzey pürüzlülüğ̈̈ & $\mathrm{R}_{\mathrm{z}}$ & {$[\mu \mathrm{m}]$} & $10,4-1,1$ \\
\hline Diş dibi genişliği & $\mathrm{S}_{\mathrm{En}}$ & {$[\mathrm{mm}]$} & 10,925 \\
\hline Eğilme diş yüksekliği & $\mathrm{h}_{\mathrm{F}}$ & {$[\mathrm{mm}]$} & 6 \\
\hline Gerilme düzeltme faktörü & $\mathrm{Y}_{\mathrm{S}}$ & {$[-]$} & 2,0 \\
\hline Dişli kalınlığ & $\mathrm{S}_{0}$ & {$[\mathrm{~mm}]$} & 7,853 \\
\hline
\end{tabular}

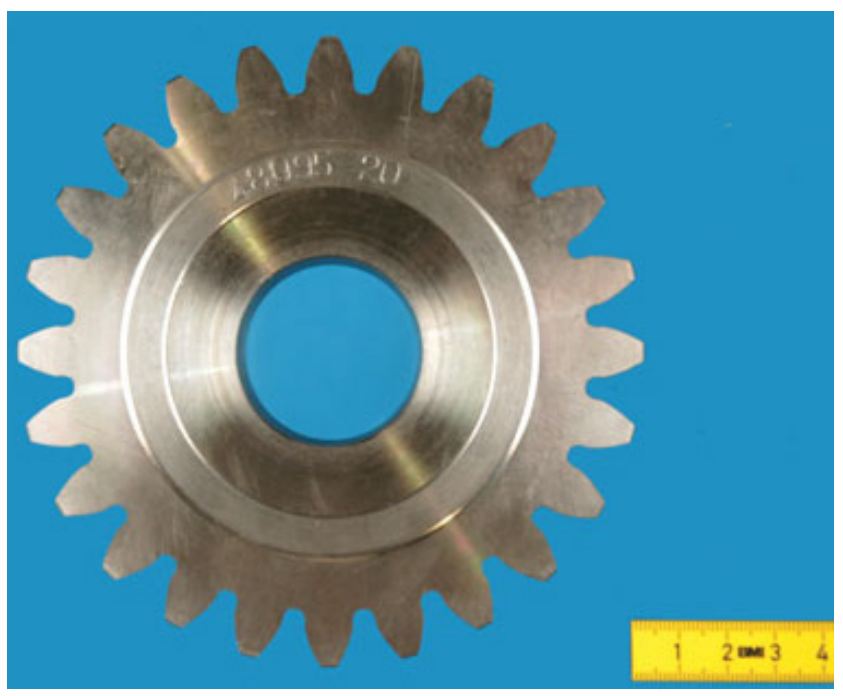

Şekil 2. Silindirik düz dişli çark

\subsubsection{MnCr5 çeliğinin kimyasal kompozisyonu}

Dişli çark malzemesi $20 \mathrm{MnCr} 5$ çeliğidir ve element kompozisyonu Tablo 2'de verilmiştir.

Tablo 2. 20MnCr5 dişli çark malzemesinin element kompozisyonu

\begin{tabular}{|l|l|l|l|l|l|l|l|l|l|l|l|}
\hline Element Kütle \% & $\mathbf{C}$ & $\mathbf{S i}$ & $\mathbf{M n}$ & $\mathbf{P}$ & $\mathbf{S}$ & $\mathbf{C r}$ & $\mathbf{M o}$ & $\mathbf{N i}$ & $\mathbf{A l}$ & $\mathbf{C u}$ & $\mathbf{N}$ \\
\hline & 0,2 & 0,25 & 1,2 & 0,009 & 0,031 & 1,25 & 0,04 & 0,21 & 0,018 & 0,15 & 0,005 \\
\hline EN 10084 & $0,17-0,22$ & $<0,4$ & $1,1-1,4$ & $<0,035$ & $<0,035$ & $1,0-1,3$ & - & - & - & - & - \\
\hline
\end{tabular}




\subsubsection{Isıl işlem}

Tüm test edilmiş dişli çarklar farklı çekirdek ve yüzey sertliğinde sertleştirilmiştir. Dişli çarklar 4 mbar asetilen atmosferinde düşük-basınçla karbürize edilmiş ve gaz ile soğutulmuştur. Farklı sertlik değerlerini elde etmek için, farklı soğutma hızları farklı gazlar ve gaz-basınçları kullanılarak uygulanmıştır. Böylece, düşük-sertlik Azot $\left(\mathrm{N}_{2}\right)$ atmosferinde 2 bar basınç altında elde edilmiştir. Orta-sertlik Azot $\left(\mathrm{N}_{2}\right)$ atmosferinde ve 6 bar basınç altında elde edilmiştir. Yüksek-sertlik Helyum (He) atmosferinde ve 20 bar basınç altında elde edilmiştir.

ISO 6336-5'e göre, sertlik ve dayanım dönüşümü mümkündür [12]. Sertlik ölçümü yüzeyden 2 [mm] derinliğe kadar gerçekleştirilmiştir. 20MnCr5 dişli malzemesinin eğilme dayanımı değerleri düşük-sertlik, orta-sertlik ve yüksek-sertlik için Tablo 3'de verilmektedir.

Tablo 3. $20 \mathrm{MnCr} 5$ malzemesinin sertlik ve dayanım ilişkisi

\begin{tabular}{|c|c|c|c|c|c|}
\hline 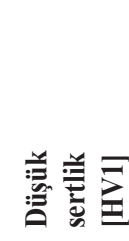 & 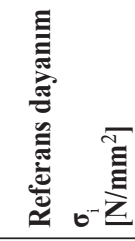 & 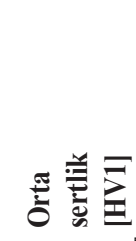 & 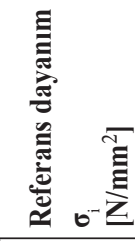 & 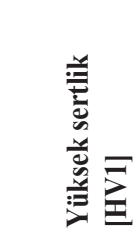 & 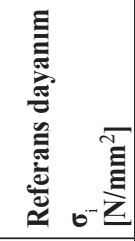 \\
\hline $\begin{array}{l}\text { Yüzey } \\
699,95\end{array}$ & \multirow[t]{2}{*}{2309,8} & $\begin{array}{l}\text { Yüzey } \\
701,3\end{array}$ & \multirow[t]{2}{*}{2335,3} & $\begin{array}{l}\text { Yüzey } \\
717,97\end{array}$ & \multirow[t]{2}{*}{2369,3} \\
\hline $\begin{array}{l}\text { Çekirdek } \\
314,6\end{array}$ & & $\begin{array}{l}\text { Çekirdek } \\
411,71\end{array}$ & & \begin{tabular}{|l} 
Çekirdek \\
451,94
\end{tabular} & \\
\hline
\end{tabular}

\subsubsection{Bilye püskürtme}

Bilye püskürtme dişlilerin yorulma dayanımını arttırmak için yaygın olarak kullanılan bir işlemdir. Bilye püskürtme esnasında yüzey tabakasına uygulanan yüksek bası gerilmeleri çatlak başlangıcı için gerilme sınırını arttırmayı amaçlar. Kontrollü bilye püskürtme işlemi yüzey sertleştirmeden sonra uygulanmıştır. Bilye püskürtme işlemi Atmen A ve Atmen N metoduna göre [10,11] yapılmıştır ve bilye püskürtme işlemine ait parametreler Tablo 4 de verilmektedir.

Tablo 4. Bilye püskürtme işlemi parametreleri

\begin{tabular}{|c|c|c|}
\hline Parametreler & Seviye 1 & Seviye 2 \\
\hline Dövme şiddeti & $\begin{array}{l}0,018-0,020 " \mathrm{~A} \\
(0,45-0,50 \mathrm{~mm} \mathrm{~A})\end{array}$ & $\begin{array}{l}0,003-0,004 " \mathrm{~N} \\
(0,075-0,1 \mathrm{~mm} \mathrm{~N})\end{array}$ \\
\hline Dövme oranı & $\% 100$ & $\% 200$ \\
\hline Bilye malzemesi & $\begin{array}{l}\text { Çelik tel kesme } \\
\emptyset 0,9 \mathrm{~mm}\end{array}$ & $\begin{array}{l}\text { Cam boncuk } \\
\varnothing 500 \mu \mathrm{m}\end{array}$ \\
\hline
\end{tabular}

\subsection{Test Prosedürü}

Dişli çarkların statik eğilme dayanımını belirlemek için dişli çarkın dişleri iki paralel temas çenesi arasında simetrik olarak sıkıştırılmıştır ve dişli çarkların dişleri statik olarak yüklenmiştir. Pulsator test makinasındaki diş konumu Şekil 3 ve Şekil 4'de gösterilmektedir.

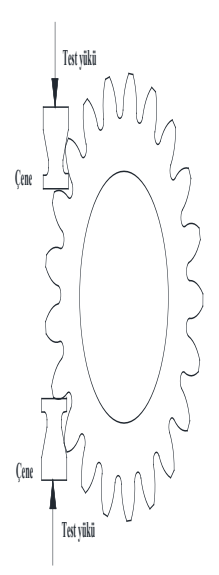

Şekil 3. Pulsator test makinasında dişin konumu

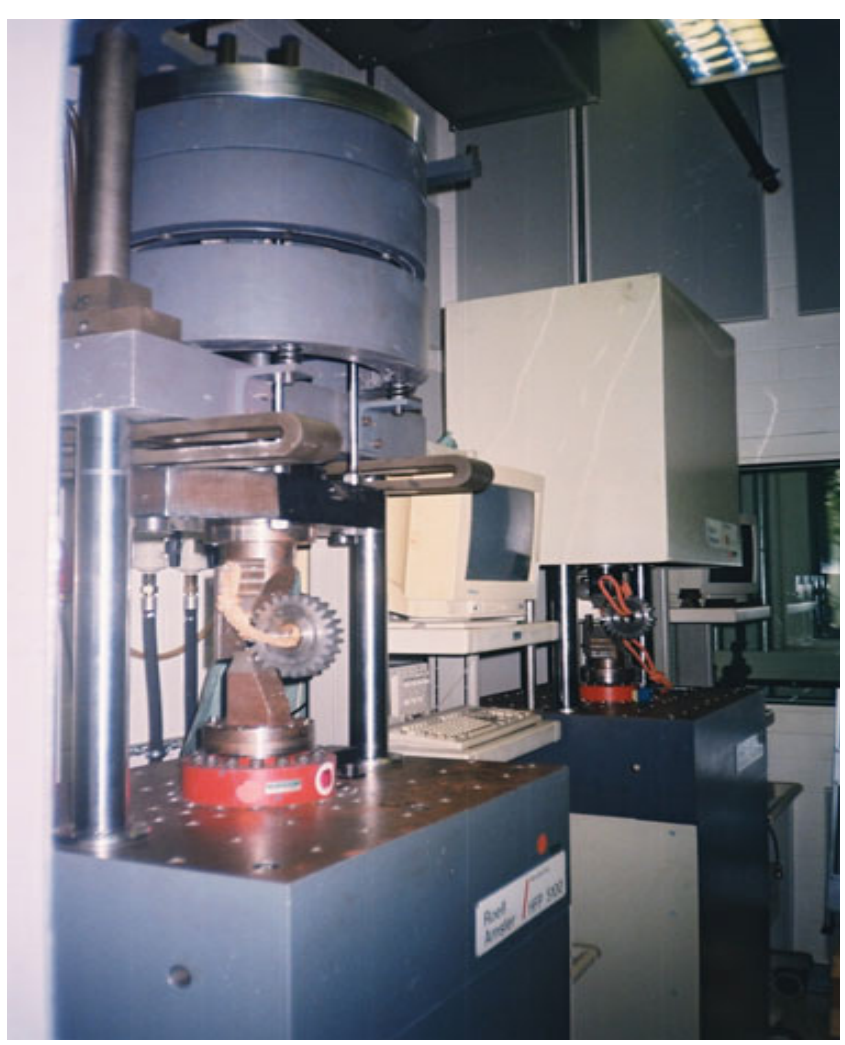

Şekil 4. Pulsator test makinası 


\subsection{Test Sonuçları}

Test makinasında kırılma hasarına karşılık gelen nominal uygulanan yük değerleri ölçülmüş ve kaydedilmiştir. Bu değerler kullanılarak hasara karşılık gelen gerilme değerleri hesaplanmıştır.

\subsubsection{Hasar yükleri ve diş-dibi gerilmeleri}

Yarı-statik eğilme testlerinin deneysel sonuçları Tablo 5 ve Tablo 6'da gösterilmektedir. Her bir grup için, dört test gerçekleştirilmiştir.

Nominal diş-dibi gerilmesi $\sigma_{F 0}$ aşağıdaki gibi hesaplanır [13]:

$$
\sigma_{F 0}=\frac{F_{n} \cos \alpha_{a}}{\frac{1}{6}\left(b S_{F n}^{2}\right)} h_{F} Y_{S}
$$

burada $F_{\mathrm{n}}$ temas doğrultusuna dik olan nominal uygulanan yük $[\mathrm{N}], \alpha_{\mathrm{a}}$ kavrama açısı $\left[{ }^{0}\right], h_{\mathrm{F}}$ yükün uygulandığı noktadan diş dibine olan eğilme momentine sebep olan mesafe [mm], $Y_{S}$ ISO 6336 ya göre gerilme düzeltme faktörü, b diş genişliği [mm] ve $S_{\mathrm{Fn}}$ kritik kesitteki diş dibi genişliği [mm], Şekil 5'de görülmektedir.

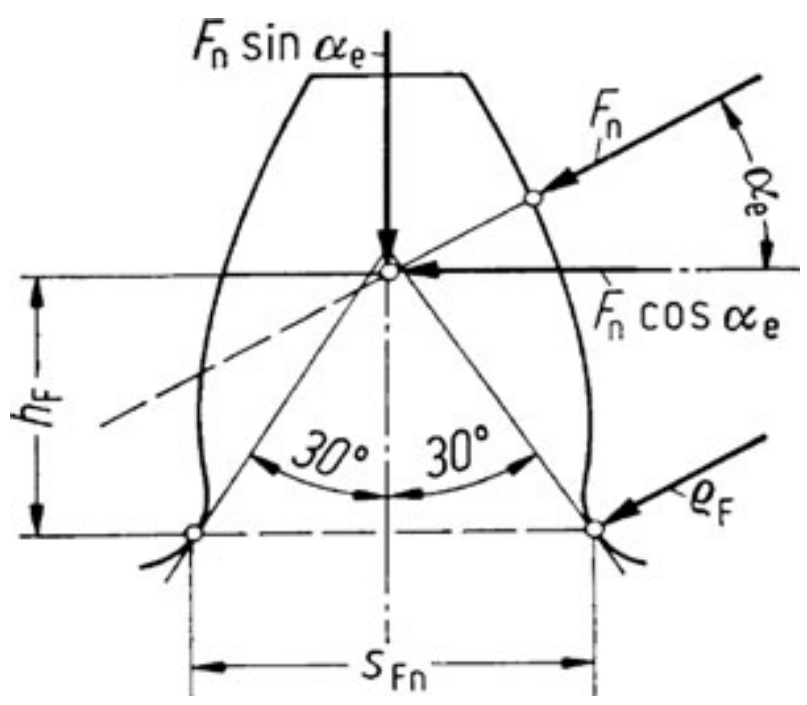

Şekil 5. Dişli çarkın dişi

\subsubsection{Hasar analizi}

Güvenirlik analizi için, bir pulsator testi üç farklı çekirdek ve yüzey-sertliğine sahip dişli çarkın dişleri için dört defa tekrarlanmıştır.

Bilye-püskürtülmüş, düşük-sertlikli dişli çarklar için statik eğilme dayanımının hasar ihtimalinin histogramı Şekil 6'da gösterilmiştir. Pulsator testi esnasında hasar durumunda nominal diş-dibi gerilmesi değeri $\sigma_{\mathrm{F} 0}, 2272\left[\mathrm{~N} / \mathrm{mm}^{2}\right]$ ile 2409 $\left[\mathrm{N} / \mathrm{mm}^{2}\right]$ arasında değişmektedir.

Bilye-püskürtülmüş, orta-sertlikli dişli çarklar için statik eğilme dayanımının hasar ihtimalinin histogramı Şekil 7'de gösterilmiştir. Pulsator testi esnasında hasar durumunda nominal diş-dibi gerilmesi değeri $\sigma_{\mathrm{F} 0}, 2480\left[\mathrm{~N} / \mathrm{mm}^{2}\right]$ ile 2491 $\left[\mathrm{N} / \mathrm{mm}^{2}\right]$ arasında değişmektedir.

Bilye-püskürtülmüş, yüksek-sertlikli dişli çarklar için statik eğilme dayanımının hasar ihtimalinin histogramı Şekil 8'de gösterilmiştir. Pulsator testi esnasında hasar durumunda nominal diş-dibi gerilmesi değeri $\sigma_{\mathrm{F} 0}, 2486\left[\mathrm{~N} / \mathrm{mm}^{2}\right]$ ile $2497\left[\mathrm{~N} / \mathrm{mm}^{2}\right]$ arasında değişmektedir.

Bilye-püskürtülmüş, düşük-sertlikli, orta-sertlikli ve yüksek-sertlikli dişli çarkların tümünde yüzey sertliği artığında, statik eğilme dayanımı artmaktadır.

Tablo 5. Bilye-püskürtülmüş dişli çarklar için statik eğilme testi

\begin{tabular}{|c|c|c|c|c|c|}
\hline \multicolumn{6}{|c|}{ sonuçları } \\
\hline Grup & $\begin{array}{l}\text { Sertleş- } \\
\text { tirme } \\
\text { İşlemi }\end{array}$ & $\begin{array}{l}\text { Yüzey } \\
\text { Sertliği } \\
\text { [HV1] }\end{array}$ & $\begin{array}{l}\text { Bilya } \\
\text { Püs- } \\
\text { kürtme }\end{array}$ & $\begin{array}{l}\text { Hasardaki } \\
\text { Statik Yük } \\
\mathbf{F}_{\mathrm{n}} \\
{[\mathbf{N}]}\end{array}$ & \begin{tabular}{|l|} 
Hasardaki \\
Diş-dibi Geril- \\
mesi \\
$\sigma_{\mathrm{F} 0}$ \\
{$\left[\mathbf{N} / \mathbf{m m}^{2}\right]$}
\end{tabular} \\
\hline 1 & $\begin{array}{l}2 \text { bar } \\
\text { Azot }\left(\mathrm{N}_{2}\right)\end{array}$ & 699,95 & $\begin{array}{l}\text { Uygu- } \\
\text { land1 }\end{array}$ & $\begin{array}{l}120240 \\
122050 \\
122050 \\
127470\end{array}$ & $\begin{array}{l}2272 \\
2306 \\
2306 \\
2409\end{array}$ \\
\hline 2 & $\begin{array}{l}6 \text { bar } \\
\text { Azot }\left(\mathrm{N}_{2}\right)\end{array}$ & 701,3 & $\begin{array}{l}\text { Uygu- } \\
\text { land1 }\end{array}$ & $\begin{array}{l}131270 \\
131540 \\
131540 \\
131810\end{array}$ & $\begin{array}{l}2480 \\
2485 \\
2485 \\
2491\end{array}$ \\
\hline 3 & $\begin{array}{l}20 \text { bar } \\
\text { Helyum } \\
(\mathrm{He})\end{array}$ & 717,97 & $\begin{array}{l}\text { Uygu- } \\
\text { land1 }\end{array}$ & $\begin{array}{l}131550 \\
131850 \\
131850 \\
132150\end{array}$ & $\begin{array}{l}2486 \\
2492 \\
2492 \\
2497\end{array}$ \\
\hline
\end{tabular}

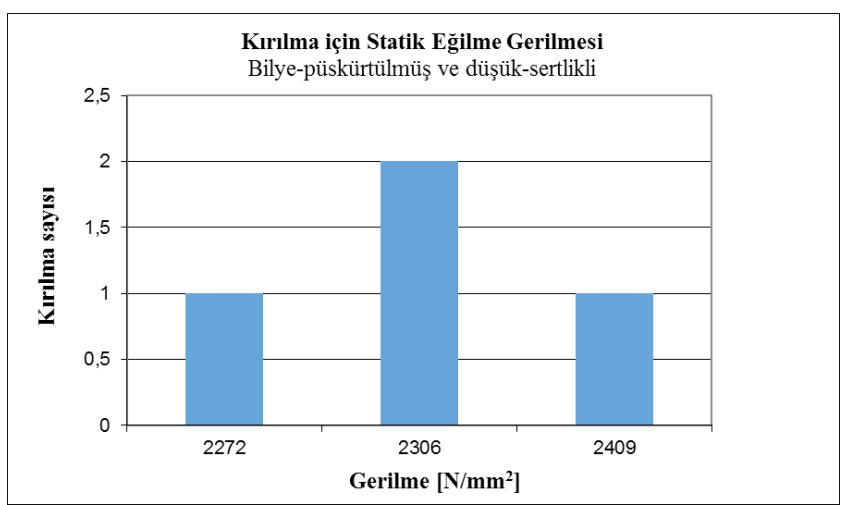

Şekil 6.Bilye-püskürtülmüş, düşük-sertlikli dişli çarlar için hasara sebep olan statik eğilme gerilmelerinin histogramı 


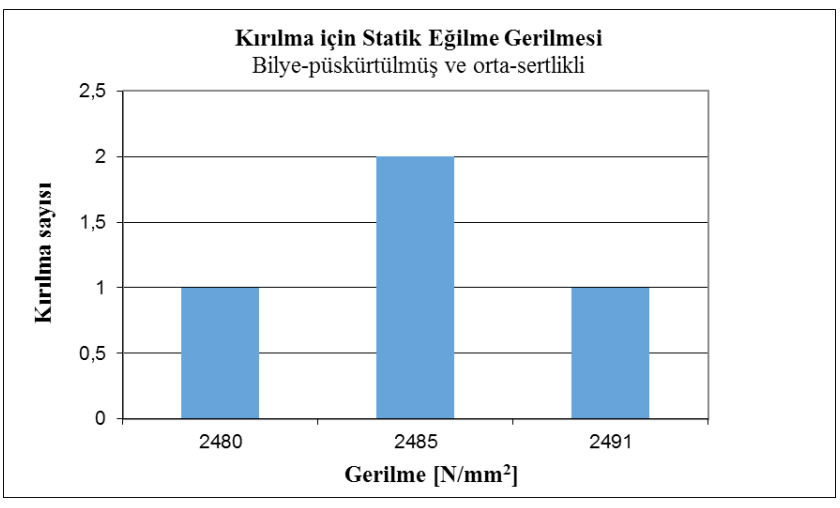

Şekil 7. Bilye-püskürtülmüş, orta sertlikli dişli çarklar için hasara sebep olan statik eğilme gerilmelerinin histogramı

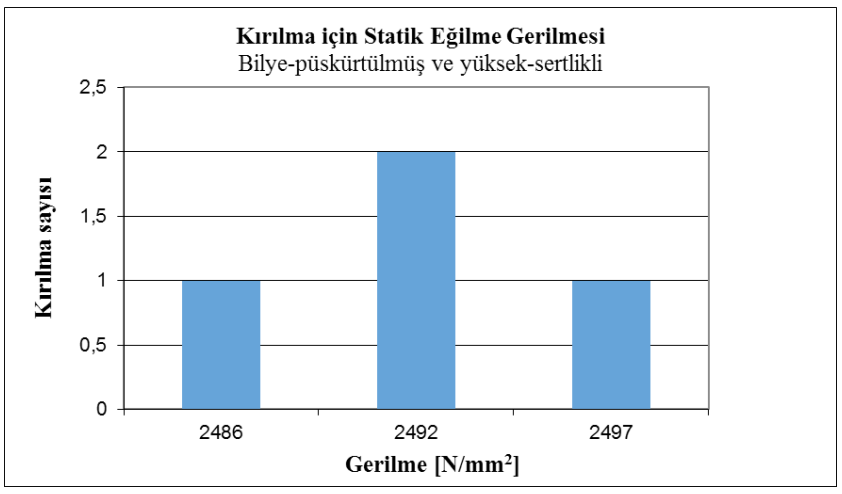

Şekil 8. Bilye-püskürtülmüş, yüksek-sertlikli dişli çarklar için hasara sebep olan statik eğilme gerilmelerinin histogramı

Bilye-püskürtülmemiş, düşük-sertlikli dişli çarklar için statik eğilme dayanımının hasar ihtimalinin histogramı Şekil 9'da gösterilmiştir. Pulsator testi esnasında hasar durumunda nominal diş-dibi gerilmesi değeri $\sigma_{\mathrm{F} 0}, 2403\left[\mathrm{~N} / \mathrm{mm}^{2}\right]$ ile $2439\left[\mathrm{~N} / \mathrm{mm}^{2}\right]$ arasında değişmektedir.

Bilye-püskürtülmemiş, orta-sertlikli dişli çarklar için statik eğilme dayanımının hasar ihtimalinin histogramı Şekil 10 'da gösterilmiştir. Pulsator testi esnasında hasar durumunda nominal diş-dibi gerilmesi değeri $\sigma_{\mathrm{F} 0}, 2419\left[\mathrm{~N} / \mathrm{mm}^{2}\right]$ ile $2508\left[\mathrm{~N} / \mathrm{mm}^{2}\right]$ arasında değişmektedir.

Bilye-püskürtülmemiş, yüksek-sertlikli dişli çarklar için statik eğilme dayanımının hasar ihtimalinin histogramı Şekil 11'de gösterilmiş̧tir. Pulsator testi esnasında hasar durumunda nominal diş-dibi gerilmesi değeri $\sigma_{\mathrm{F}}, 2457$ [N/mm²] ile $2519\left[\mathrm{~N} / \mathrm{mm}^{2}\right]$ arasında değişmektedir.

Bilye-püskürtülmemiş, düşük-sertlikli, orta-sertlikli ve yüksek-sertlikli dişli çarkların tümünde yüzey sertliği artığında, statik eğilme dayanımı artmaktadır.
Tablo 6. Bilye-püskürtülmemiş dişli çarklar için statik eğilme testi sonuçları

\begin{tabular}{|l|l|l|l|l|l|}
\hline Grup & $\begin{array}{l}\text { Sertleştirme } \\
\text { İşlemi }\end{array}$ & $\begin{array}{l}\text { Yüzey } \\
\text { Sertliği } \\
\text { [HV1] }\end{array}$ & $\begin{array}{l}\text { Bilya Püs- } \\
\text { kürtme }\end{array}$ & $\begin{array}{l}\text { Hasar- } \\
\text { daki Sta- } \\
\text { tik Yük } \\
\mathbf{F}_{\mathrm{n}} \\
{[\mathbf{N}]}\end{array}$ & $\begin{array}{l}\text { Hasar- } \\
\text { daki } \\
\text { Diş-dibi } \\
\text { Gerilmesi } \\
\boldsymbol{\sigma}_{\mathrm{F} 0} \\
{\left[\mathbf{N} / \mathbf{m m}^{2}\right]}\end{array}$ \\
\hline $\mathbf{1}$ & 2 bar & 699,95 & Uygulan- & 127180 & 2403 \\
& Azot $\left(\mathrm{N}_{2}\right)$ & & madı & 128910 & 2436 \\
& & & & 128910 & 2436 \\
& & & & 129080 & 2439 \\
\hline $\mathbf{2}$ & 6 bar & 701,3 & Uygulan- & 128030 & 2419 \\
& Azot $\left(\mathrm{N}_{2}\right)$ & & madi & 129080 & 2439 \\
& & & & 129080 & 2439 \\
& & & & 132710 & 2508 \\
\hline $\mathbf{3}$ & 20 bar & 717,97 & Uygulan- & 130030 & 2457 \\
& Helyum $(\mathrm{He})$ & & madi & 131680 & 2488 \\
& & & & 131680 & 2488 \\
& & & & 133340 & 2519 \\
\hline
\end{tabular}

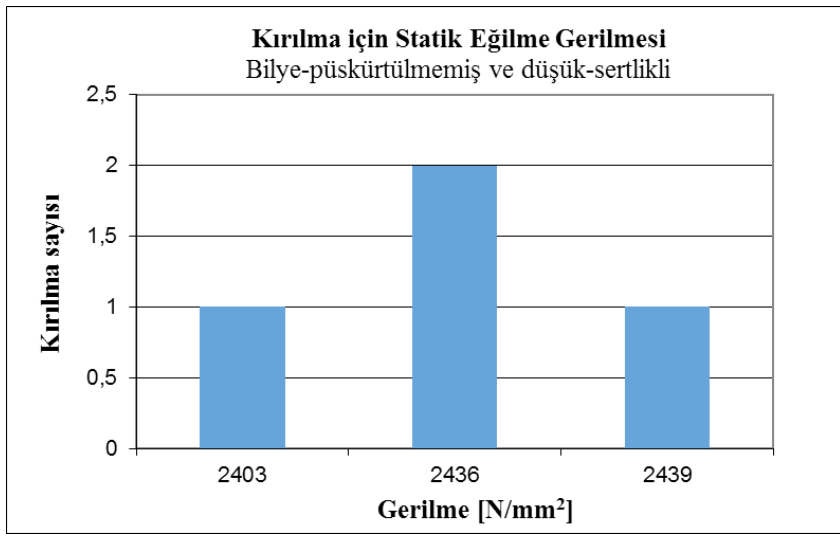

Şekil 9. Bilye-püskürtülmemiş, düşük-sertlikli dişli çarklar için hasara sebep olan statik eğilme gerilmelerinin histogramı

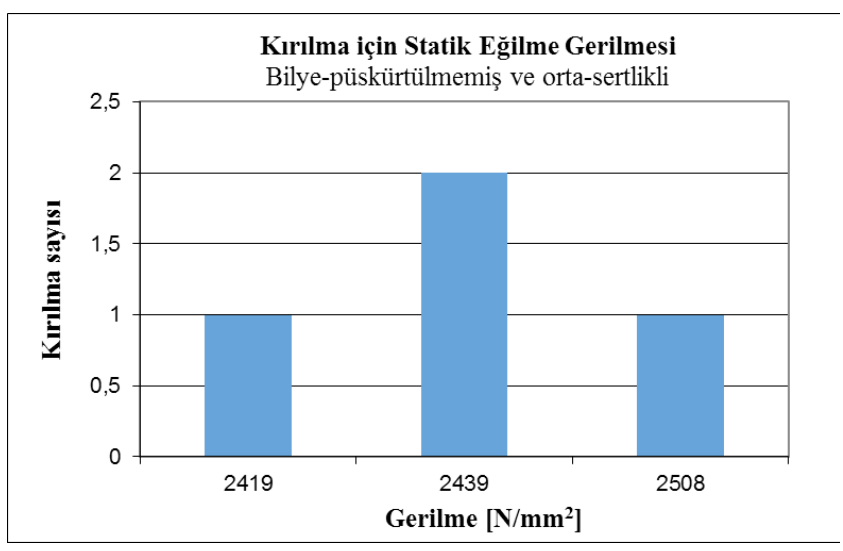

Şekil 10. Bilye-püskürtülmemiş, orta sertlikli dişli çarklar için hasara sebep olan statik eğilme gerilmelerinin histogramı 


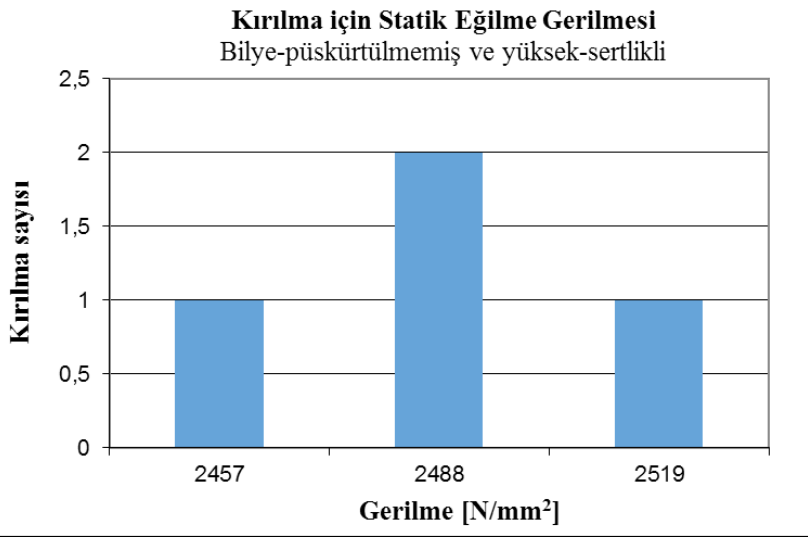

Şekil 11. Bilye-püskürtülmemiş, yüksek-sertlikli dişli çarklar için hasara sebep olan statik eğilme gerilmelerinin histogramı

\section{III.GÜVENİRLIKK ANALIZİ}

Güvenirlik analizi için, statik eğilme dayanımının ortalama değerleri, standart sapmaları ve standart değişkenleri hesaplanmıştır ve bu değerler Tablo 7 ve Tablo 8'de sunulmuştur.

\subsection{Hasar İhtimali Fonksiyonu}

Hasar ihtimali hesaplamaları için aşağıdaki fonksiyon kullanılmıştır [14]:

$$
f(\sigma)=\frac{1}{S_{\sigma} \sqrt{2 . \pi}} \exp \left[-\frac{\left(\sigma-\sigma_{m}\right)^{2}}{2 . S_{\sigma}^{2}}\right]
$$

burada $S_{\sigma}$ standart sapma, $\sigma$ nominal gerilme ve $\sigma_{m}$ gerilmenin ortalama değeridir.

\subsection{Ortalama Değer}

Gerilmenin ortalama değeri, $\sigma_{\mathrm{m}}\left[\mathrm{N} / \mathrm{mm}^{2}\right]$ için aşağıdaki fonksiyon kullanılmıştır [14]:

$$
\sigma_{m}=\frac{1}{n} \sum_{i=1}^{n} \sigma_{i}
$$

burada $n$ testlerin sayısı ve $\sigma_{\mathrm{i}}\left[\mathrm{N} / \mathrm{mm}^{2}\right]$ her bir test için ölçülen gerilmedir.

\subsection{Standart Sapma}

Gerilmenin standart sapması $S_{\sigma}\left[\mathrm{N} / \mathrm{mm}^{2}\right]$ için aşağıdaki fonksiyon kullanılmıştır [14]:

$$
S_{\sigma}=\left[\frac{1}{n-1} \sum_{i=1}^{n}\left(\sigma_{i}-\sigma_{m}\right)^{2}\right]^{1 / 2}
$$

burada $\sigma_{\mathrm{i}}\left[\mathrm{N} / \mathrm{mm}^{2}\right]$ her bir test için ölçülen değerdir ve $\sigma_{\mathrm{m}}$ $\left[\mathrm{N} / \mathrm{mm}^{2}\right]$ gerilmenin ortalama değeridir.

\subsection{Standart Değişken}

Gerilmenin standart değişkeni $z_{\alpha}$ için aşağıdaki fonksiyon kullanılmıştır [14]:

$$
z_{\alpha}=\frac{\sigma_{i}-\sigma_{m}}{S_{\sigma}}
$$

burada $\sigma_{\mathrm{i}}\left[\mathrm{N} / \mathrm{mm}^{2}\right]$ malzemenin literatürde verilen static eğilme dayanımıdır.

\section{SONUÇLAR VE TARTIŞMA}

Bilye-püskürtülmüş dişli çarklar için statik eğilme dayanımının güvenirlik analizi parametreleri Tablo 7'de sunulmaktadır.

Tablo 7. Bilye-püskürtülmüş dişli çarkların güvenirlik analizi parametreleri

\begin{tabular}{|l|l|l|l|l|l|l|}
\hline Grup & $\begin{array}{l}\text { Sertleștirme } \\
\text { işlemi }\end{array}$ & $\begin{array}{l}\text { Referans } \\
\text { dayanım } \\
\boldsymbol{\sigma}_{\mathrm{i}} \\
{\left[\mathbf{N} / \mathbf{m m}^{2}\right]}\end{array}$ & $\begin{array}{l}\text { Ortalama } \\
\text { değer } \\
\boldsymbol{\sigma}_{\mathrm{m}} \\
{\left[\mathbf{N} / \mathbf{m m}^{2}\right]}\end{array}$ & $\begin{array}{l}\text { Standart } \\
\text { sapma } \\
\mathbf{S}_{\sigma} \\
{\left[\mathbf{N} / \mathbf{m m}^{2}\right]}\end{array}$ & $\begin{array}{l}\text { Standart } \\
\text { değişken } \\
\mathbf{z}_{\sigma} \\
{[-]}\end{array}$ & $\begin{array}{l}\text { Güve- } \\
\text { nirlik } \\
\mathbf{R}\end{array}$ \\
\hline 1 & $\begin{array}{l}2 \text { bar } \\
\text { Azot }\left(\mathrm{N}_{2}\right)\end{array}$ & 2309,8 & 2323,25 & 59,37 & $-0,2265$ & $>99$ \\
\hline 2 & $\begin{array}{l}6 \text { bar } \\
\text { Azot }\left(\mathrm{N}_{2}\right)\end{array}$ & 2335,3 & 2485,25 & 4,5 & $-33,3222$ & $>99$ \\
\hline 3 & $\begin{array}{l}20 \text { bar } \\
\text { Helyum } \\
(\mathrm{He})\end{array}$ & 2369,3 & 2491,75 & 4,5 & $-27,2111$ & $>99$ \\
\hline
\end{tabular}

Bilye-püskürtülmüş ve düşük sertlikli dişli çarkların (1.grup), kırılma hasarının gerçekleştiği ortalama gerilme değeri $\sigma_{\mathrm{m}}$, referans dayanım değeri $\sigma_{\mathrm{i}}$ 'den $\% 0,58$ daha yüksektir.

Bilye-püskürtülmüş ve orta sertlikli dişli çarkların (2.grup), kırılma hasarının gerçekleştiği ortalama gerilme değeri $\sigma_{\mathrm{m}}$, referans dayanım değeri $\sigma_{\mathrm{i}}$ 'den $\%$, 4 , daha yüksektir.

Bilye-püskürtülmüş ve yüksek sertlikli dişli çarkların (3.grup), kırılma hasarının gerçekleştiği ortalama gerilme değeri $\sigma_{\mathrm{m}}$, referans dayanım değeri $\sigma_{\mathrm{i}}{ }^{\prime}$ den $\% 5,2$ daha yüksektir. 
Bilye-püskürtülmemiş dişli çarklar için statik eğilme dayanımının güvenirlik parametreleri Tablo 8'de sunulmaktadır.

Tablo 8. Bilye-püskürtülmemiş dişli çarkların güvenirlik analizi parametreleri

\begin{tabular}{|l|l|l|l|l|l|l|}
\hline Grup & $\begin{array}{l}\text { Sertleştirme } \\
\text { işlemi }\end{array}$ & $\begin{array}{l}\text { Referans } \\
\text { dayanım } \\
\boldsymbol{\sigma}_{\mathrm{i}} \\
{\left[\mathbf{N} / \mathbf{m m}^{2}\right]}\end{array}$ & $\begin{array}{l}\text { Ortalama } \\
\text { değer } \\
\boldsymbol{\sigma}_{\mathrm{m}} \\
{\left[\mathbf{N} / \mathbf{m m}^{2}\right]}\end{array}$ & $\begin{array}{l}\text { Standart } \\
\text { sapma } \\
\mathbf{S}_{\sigma} \\
{\left[\mathbf{N} / \mathbf{m m}^{2}\right]}\end{array}$ & $\begin{array}{l}\text { Standart } \\
\text { değişken } \\
\mathbf{z}_{\sigma} \\
{[-]}\end{array}$ & $\begin{array}{l}\text { Güve- } \\
\text { nirlik } \\
\mathbf{R} \\
{[\%]}\end{array}$ \\
\hline 1 & $\begin{array}{l}2 \text { bar } \\
\text { Azot }\left(\mathrm{N}_{2}\right)\end{array}$ & 2309,8 & 2428,5 & 17,05 & $-6,9618$ & $>99$ \\
\hline 2 & $\begin{array}{l}6 \text { bar } \\
\text { Azot }\left(\mathrm{N}_{2}\right)\end{array}$ & 2335,3 & 2451,25 & 38,99 & $-2,9768$ & $>99$ \\
\hline 3 & $\begin{array}{l}20 \text { bar } \\
\text { Helyum } \\
(\mathrm{He})\end{array}$ & 2369,3 & 2488 & 25,31 & $-4,6898$ & $>99$ \\
\hline
\end{tabular}

Bilye-püskürtülmemiş ve düşük sertlikli dişli çarkların (1.grup), kırılma hasarının gerçekleştiği ortalama gerilme değeri $\sigma_{\mathrm{m}}$, referans dayanım değeri $\sigma_{\mathrm{i}}$ 'den $\% 5,1$ daha yüksektir.

Bilye-püskürtülmemiş ve düşük sertlikli dişli çarkların (3.grup), kırılma hasarının gerçekleştiği ortalama gerilme değeri $\sigma_{m}$, referans dayanım değeri $\sigma_{i}$ 'den $\% 4,9$ daha yüksektir.

Bilye-püskürtülmemiş ve düşük sertlikli dişli çarkların (2.grup), kırılma hasarının gerçekleştiği ortalama gerilme değeri $\sigma_{m}$, referans dayanım değeri $\sigma_{i}$ 'den $\% 5,0$ daha yüksektir.

Bilye-püskürtülmüş ve bilye-püskürtülmemiş dişli çarkların statik eğilme dayanımı karşılaştırıldığında; düşük-sertlik için \% 4,5 orta sertlik için \% 1,4 ve yüksek sertlik için \% 0,15 fark vardir.

Bilye-püskürtme işleminin dişli çarkların statik eğilme dayanımını arttırıc1-olumlu bir etkisinin olmadığı görülmüştür.

Çekirdek sertliğinin, dişli çarkların statik eğilme dayanımının belirlenmesinde, hasar oluşumu yüzeyden başladığından dolayı belirgin bir etkisinin olmadığı görülmüştür.

Dişli çark dişlerinin statik eğilme dayanımının ortalama değerleri 20MNcr5 dişli çark malzemesinin statik eğilme dayanım değeri olan $\sigma_{\mathrm{e}}=2180\left[\mathrm{~N} / \mathrm{mm}^{2}\right]$ den $(650 \mathrm{HV}$ ve yukarısı için) [12] daha büyüktür.

\subsection{Hasar Yüzeyinin Makro-Yapısı}

Dişli çarkın hasar yüzeyinin makro-yapısı bir "PROGRESS 3012 Digital optik kamera" ile gözlemlenmiştir. Bilye-püskürtülmüş ve bilye-püskürtülmemiş dişli çarklar için hasar yüzeylerinin görünümleri Şekil 12-13'de gösterilmektedir. Kırılma yüzeyleri çatlağın maksimum çekme gerilmesine göre yüzeyden başladığı tipik statik yükleme hasarları görünümündedir. Şekil 14 diş-dibi eğilme hasarının diş simetri ekseni ile $30^{0}$ eğim yapan doğrunun diş-dibi kavislerine teğet olduğu noktada olduğunu gösterir.

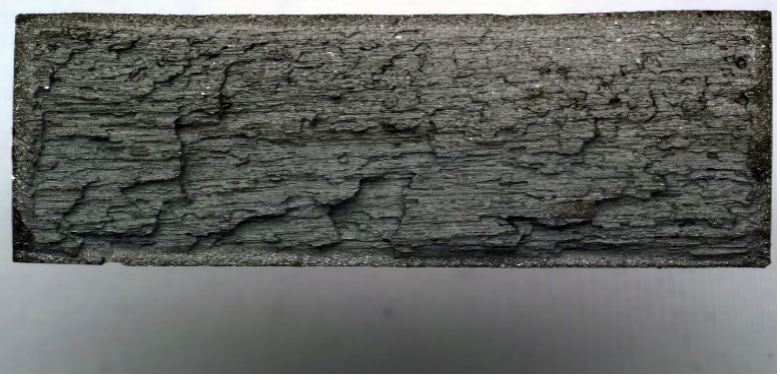

Şekil 12. Bir bilye-püskürtülmüş, yüksek-sertlikli dişli çarkın dişinin kırılma yüzeyi

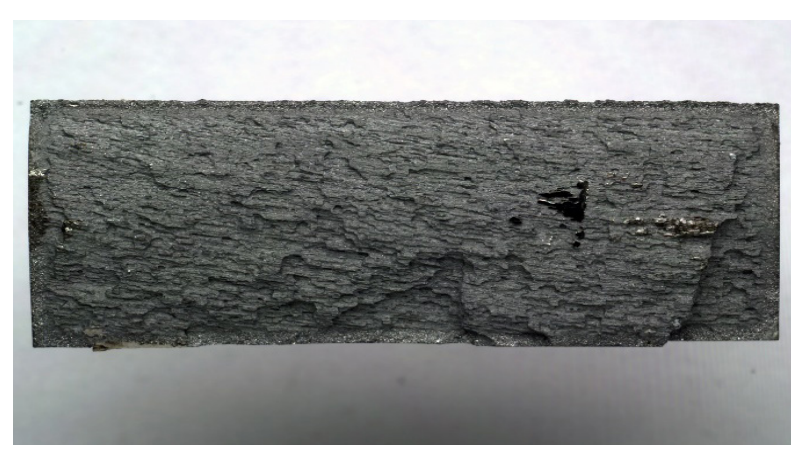

Şekil 13. Bir bilye-püskürtülmemiş, yüksek-sertlikli dişli çarkın dişinin kırılma yüzeyi

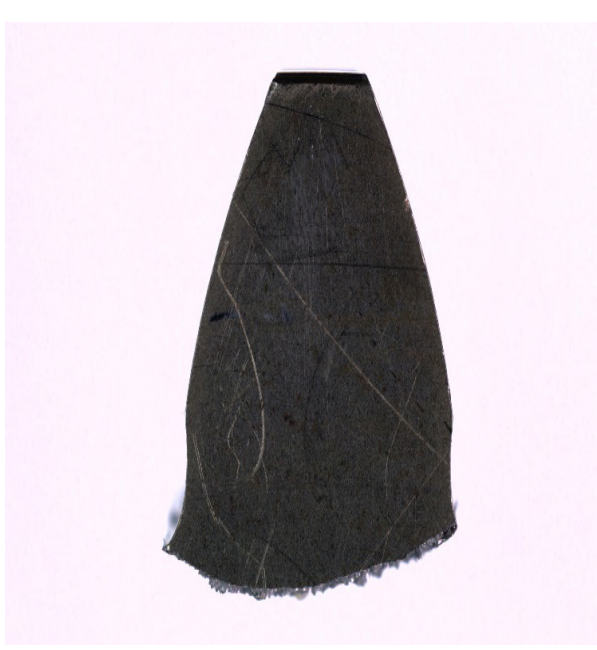

Şekil 14. Silindirik düz dişli çarkın dişinin hasar görünümü 


\section{SONUÇLAR}

Bu çalışmada, farklı sertlikteki silindirik düz dişli çarkların dişinin statik eğilme dayanımı güvenirlik temelinde deneysel olarak incelenmiştir. Bu amaçla, bilye-püskürtülmüş ve bilye-püskürtülmemiş düşük-sertlikli, orta-sertlikli ve yüksek-sertlikli gibi farklı çekirdek ve yüzey sertlik değerlerine sahip dişli çarklar pulsator test makinasında test edilmiştir.

Test sonuçları sertliğin dişli çarkların dişlerinin statik eğilme dayanımlarının belirlenmesinde iyi bir referans olduğunu göstermiştir.

i. Hasar yüzeyinin gözlemlenmesiyle, bir tipik statik yükleme hasarı yüzeyi ve hasarın diş simetri ekseni ile $30^{0}$ eğim yapan doğrunun diş kavislerine teğet olan noktada olduğu görülmektedir.

ii. Sertlik değerinin artması dişli çarkın diş-dibi eğilme dayanımının artmasıyla sonuçlanmaktadır.

Bir yüksek eğilme dayanımı değeri 20 bar Helyum (He) atmosferinde 1sıl işlem görmüş yüksek-sertlikli dişli çarklar için elde edilmiştir.

iii. Düşük-sertlikli dişli çarklar, 2 bar Azot $\left(\mathrm{N}_{2}\right)$ atmosferinde sertleștirilerek elde edilmiştir. Düşüksertlikli dişli çarkların güvenirlik seviyeleri ( $\mathrm{R}>99 \%)$ istenilen değerleri sağlamaktadır.

iv. Orta-sertlikli dişli çarklar, 6 bar Azot $\left(\mathrm{N}_{2}\right)$ atmosferinde sertleştirilerek elde edilmiştir. Orta-sertlikli dişli çarkların güvenirlik seviyeleri $(\mathrm{R}>99 \%)$ istenilen değerleri sağlamaktadır.

v. Yüksek-sertlikli dişli çarklar, 20 bar Helyum (He) atmosferinde sertleştirilerek elde edilmiştir. Yükseksertlikli dişli çarkların güvenirlik seviyeleri $(\mathrm{R}>99 \%)$ istenilen değerleri sağlamaktadır.

vi. Bilye-püskürtme dişli çarkların değişken eğilme dayanımlarının iyileştirilmesinde etkili bir işlem olmasına rağmen, dişlilerin statik eğilme dayanımlarının iyileştirilmesinde hiç etkili olmadığı belirlenmiştir.

vii. Çekirdek sertliğinin, dişli çarkların statik eğilme dayanımının belirlenmesinde, hasar oluşumu yüzeyden başladığından dolayı, belirgin bir etkisinin olmadığı görülmüştür.

viii.Bütün test gerilmeleri referans dayanım değerlerinin üzerinde olduğundan, bütün dişli çarkların güvenirliklerinin $99 \%$ civarında olduğunu tahmin etmek mümkün olmasına rağmen, bir güvenirlik analizi ürün güvenirliğini tahmin etmek için her bir imalat ve tasarım aşamasında gereklidir. ix. Dişli çarklar yaygın olarak mekanik sistemlerde kullanıldığından, elde edilen sonuçlar ve kullanılan metotlar dişli imalatçıları için faydalıdır.

\section{Teșekkür}

Yazar, Münih Teknik Üniversitesi, FZG Dişli Çark Araştırma Merkezi'nde misafir araştırmacı olduğu süreçte katkılarından dolayı Prof. Dr.-Ing. Bernd Robert Höhn'e teşekkür eder.

\section{Kaynaklar}

[1] Juvinal, Robert C. and Marshek, Kurt M., (2000). Fundamentals of Machine Component Design, John Wiley \& Sons, Inc., U.S.A.

[2] William D. Callister, Jr., (2007). Materials Science and Engineering, An Introduction, John Wiley \& Sohns, Inc., U.S.A.

[3] Karin Björkeborn, Uta Klement, Hans-Börje Oskarson, (2010). Study of microstructureal influences on machinability of case hardening steel, Int. J. of Advanced Manufacturing Technology, 49, 441-446.

[4] A.T. Vielma, V.Llaneza, F.J. Belzunce, (2014). Shot peening intensity optimisation to increasethe fatigue life of a quenched and tempered structural steel, Procedia Engineering 74, 273-278.

[5] S. B. Mahagaonkar, P. K. Brahmankar, C. Y. Seemikeri, (2008). Effect of shot peening parameters on microhardness of AISI 1045 and 316L material: an analysis using design of experiment, Int. J. of Advanced Manufacturing Technology, 38, 563-564.

[6] R. Yang, X Zhang, D. Mallipeddi, N. Angelou, H.L. Toftegard, Y.Li, J. Ahlström, L. Lorentzen, G. Wu, X. Huang, (2017). Effect of shot peening on the residual stress and mechanical behaviour of low-temperature and high-temperature annealed martensitic gear steel 18CrNiMo7-7, IOP Conf. Series: Materials Science and Engineering, 219, 1-7.

[7] Mehmet Bozca, (2008). Influence of core hardness on bending strength of tooth in cylindrical gears under quasistatic loading conditions, Fatigue \& Fracture of Engineering Materials \& Structures, 31, 902-910.

[8] VDI 4001: Verein Deutscher Ingenieure -Handbuch Technishe Zuverlässigkeit.

[9] Fang Jun Zuo, Le Yu, Jinhua Mi, Zheng Liu, Hong Zhong Huang, (2015). Reliability analysis of gear transmission with considering failure correlation, Maintenance and Reliability, 17 (4) 617-623.

[10] Alessandro Stenico, (2007). Werkstoffmechanische Untersuchungen zur Zahnfußtragfähigkeit einsatzgehärteter Zahnräder, Institut für Maschinen - und Fahrzeugtechnik Lehrstuhl für Maschinenelemente, Technische Universität München, München. 
[11] Hamza Kemal Akyıldız, (1998). Bilyeli dövmenin $\mathrm{Fe}+\% 2 \mathrm{Cu}$ +\%0,5 C Toz Metal Çeliğin Yorulma Davranışına Etkisi, Yüksek Lisans Tezi, Gazi Üniversitesi, Fen BilimleriEnstitüsü, Ankara.

[12] ISO 6336-5, Calculation of load capacity of spur and helical gears-Part 5: Strengthand quality of materials.
[13] ISO 6336-3, Calculation of load capacity of spur and helical gears-Part 3: Calculation of tooth bending strength.

[14] Bernd Bertsche, "Reliability in Automotive and Mechanical Engineering”, Springer,2008. 